\title{
Pressure Fluctuation in a Vaned Diffuser Downstream from a Centrifugal Pump Impeller
}

\author{
Akinori Furukawa and Hisasada Takahara \\ Faculty of Engineering, Kyushu University, Fukuoka, Japan \\ Takahiro Nakagawa and Yusuke Ono \\ Graduate School of Engineering, Kyushu University, Fukuoka, Japan
}

Periodic flows downstream from a centrifugal pump impeller in vaneless and vaned diffusers were measured by using a single hole yawmeter and a phase-locked sampling method. The flows were also calculated by an inviscid flow analysis using the blade-surface singularity method. The periodic variations in calculated static pressure with the impeller rotating quantitatively agree well with the measured ones. The flow behaviors in the vaned diffuser are discussed, citing measured and calculated results. The potential interaction between the impeller and the diffuser blades appears more strongly than the impeller-wake interaction. The appearance of static pressure fluctuations due to the impeller's rotating in the fully vaned zone is different from that in the semivaned zone of the diffuser. The existence of the peripheral blade surface of the impeller outlet with an outlet edge of the pressure surface causes violent pressure fluctuations in the vaned diffuser.

Keywords Blade rows interaction, Centrifugal pump impeller, Diffuser, Flow measurement, Inviscid flow analysis, Pressure fluctuation

Diffuser pumps with high head have recently been used in various kinds of large-scale industrial plants, whereas small pumps with higher speeds are demanded by limitations on manufacturing cost and installation space. The performance of a diffuser pump with high head would be improved by the reduction of flow losses in the diffuser, yielding high pressure recovery, and in the impeller. Additionally, in a diffuser with a combined impeller and vane, the interaction of the impeller and diffuser blades

Received 25 June 2002; accepted 1 July 2002.

Address correspondence to Akinori Furukawa, Department of Engineering, Kyushu University 36, 6-10-1 Hakozaki, Higashi-ku, Fukuoka, 812-8581, Japan. E-mail: fmfuru@ @ech.kyushu-u.ac.jp might cause a severe vibration problem. Regarding the flow in a diffuser downstream from the impeller: although there are many experimental and theoretical reports (Arndt et al., 1990; Qin and Tsukamoto, 1997; Shi and Tsukamoto, 1999; Sinha and Katz, 1999; Zhu and Kamemoto, 1999), at the present stage, it is not sufficient to understand flow mechanism in the diffuser and the interaction of the impeller and diffuser blades.

In our previous report (Furukawa et al., 2000), it was shown that even the solution of an inviscid flow analysis by simple calculations was able to simulate the real flow in a vaneless diffuser downstream of a centrifugal impeller. In this article, the method is extended to a flow in an impeller-and-vaned-diffuser combination, and calculated and measured results are compared. The velocity and pressure fluctuations caused in the vaned diffuser by the interaction of the blades is clarified, and the effects of impeller and diffuser blade positions on the pressure fluctuation are discussed.

\section{EXPERIMENTAL APPARATUS}

Figure 1 shows a sectional view of the pump equipment with a vertical rotating shaft. Flowing into the impeller, 1, through a Venturi flowmeter and boost pump from an open tank, water is discharged to a parallel-walled diffuser, 2, with a height of $b=30 \mathrm{~mm}$, which is the same as the impeller blade height; the water overflows after forming a free surface in channel, 3 , which is equipped to produce an axisymmetrically periodic flow; and it then returns to the open tank. In this experiment, an oil seal was attached to the pump's suction cover-ring to suppress a recirculating flow from the outlet to the inlet through a space between the impeller shroud and the casing.

Figure 2 shows the shapes of the test impeller and diffuser. The impeller has six two-dimensional blades $\left(Z_{i}=6\right)$ with the inlet and outlet diameters of 200 and $400 \mathrm{~mm}$. The suction and pressure surface-blade outlet angles are $\beta_{b 2 s}=\beta_{b 2 p}=18.1$ degrees, and the peripheral blade thickness is $t_{\theta 2}=35.0 \mathrm{~mm}$ at the outlet. Eleven two-dimensional blades $\left(Z_{d}=11\right)$ with the inlet 


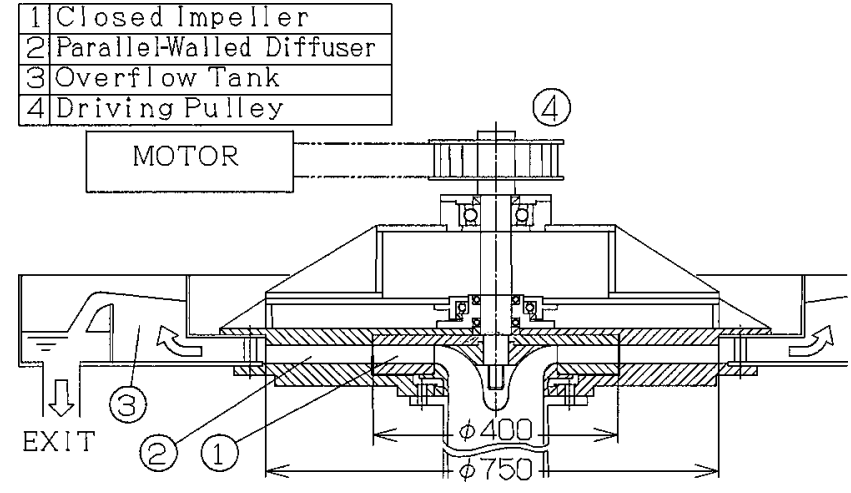

FIGURE 1

Sectional view of pump equipment.

angle $\alpha_{b 3 c}=22.8$ degrees on a blade center line and the inlet and outlet diameters of 420 and $600 \mathrm{~mm}$ (corresponding to the radius ratio of the impeller outlet $R=r / r_{2}=1.05$ and 1.50) were installed in the diffuser. The diffuser blade was cut by a circular arc of the radius of 3 and $110 \mathrm{~mm}$ on the inlet suction (convex) and pressure (concave) surfaces, respectively. In the case of $Z_{i}=6$ and $Z_{d}=11$, the dominant frequency of the pressure fluctuation in the diffuser due to the impeller blades' rotating takes $2 Z_{i} N$, where $N$ is a rotational speed of the impeller.

The flow-measuring probes were placed at six radial sections of the ratio $R=1.03,1.06,1.10,1.15,1.28$, and 1.50 on the diffuser wall of the impeller shroud side. The opposite wall of the disk side is movable so flow can be measured at five circumferential positions, line 1 through line 5 , on the diffuser's blade-to-blade passage (see Fig. 2). The periodic flow with the static pressure $p$ and the absolute velocity $V$, the radial and circumferential components of which denote $V_{r}$ and $V_{\theta}$, respectively, downstream of the impeller was measured at seven positions $-0, \pm 6, \pm 12$, and $\pm 13.5 \mathrm{~mm}$ from the center of the diffuser's height. A rotating total-pressure probe with a single hole (Takahara et al., 1989) was used with the sampling method of the phase-locked to the impeller's rotation. The pressure at the probe head was transferred to the sensor through the connecting pipe, which is filled with a silicone oil. The response frequency of the pressure measuring system was about $1 \mathrm{kHz}$.

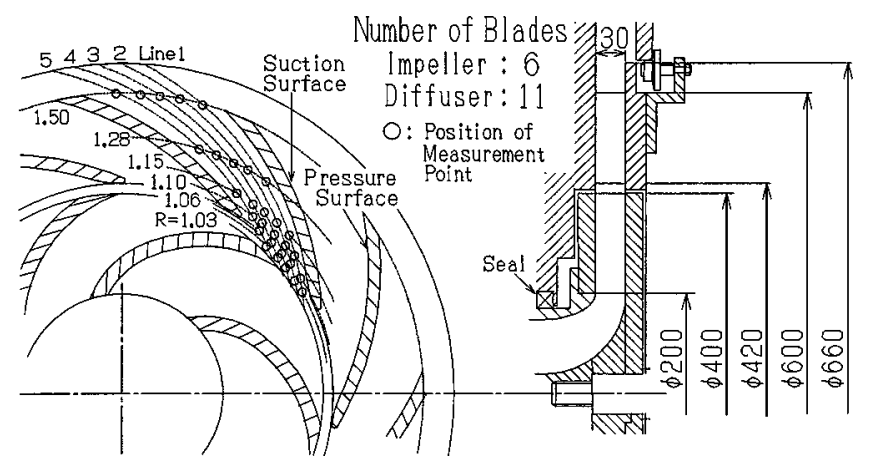

FIGURE 2

Test impellers and a vaned diffuser.
The pump impeller speed was always kept at $N=200 \mathrm{rpm}$. The flow measurement was executed at a flow coefficient of $\phi=0.146$, where the waving motion of the free surface in channel, 3, was not observed. Here the flow coefficient $\phi$ was denoted as the ratio of the averaged radial velocity component $V_{r 2}$ to the impeller's rotating velocity $U_{2}$ at the impeller outlet, and the pressure coefficient $\psi_{s}$ was denoted as the ratio of the static pressure rise, based on the pump's inlet total pressure of $\rho U_{2}^{2} / 2$, where $\rho$ is the water density.

\section{DESCRIPTION OF INVISCID FLOW CALCULATION}

Figure 3 shows the calculated and measured results in the case of the combination of an impeller and a vaneless diffuser. In this calculation, taking into account the three-dimensional boundary layer model (Furukawa et al., 1987, 1990), discrete vortexes are distributed on the impeller blade surfaces, including the inlet and outlet peripheral surfaces, in order to reproduce the blade shape precisely. This method is called the blade-surface singularity method. The strength of the vortex at the outlet edge of the suction surface is assumed to take zero as the Kutta condition, and other discrete vortex are solved from the tangential conditions of the relative flow along the blade surface. The horizontal axis $\theta$ in Figure 3 is denoted as the circumferential position relative to the impeller, rotating where the positions of the outlet edge of the impeller's pressure surface correspond to $\theta=0$ degrees and -60 degrees. As can be seen in Figure 3, both results give the same variations in velocity and pressure with the impeller rotating, such as a low-pressure and velocity region near the same $\theta$ position that corresponds to the outlet edge of the blade's pressure surface. The behavior of wake, which flows along the relative streamline, cannot be simulated because of inviscid flow calculation.

The good agreement between calculated and measured results in Figure 3 encourages the extending of this method to calculations involving a combined impeller and vaned diffuser. In the extended calculation, discrete vortexes are also distributed on the impeller and diffuser blade surfaces; their strength is obtained from the tangential condition of the flow on blade surfaces with the Kutta condition, under the condition of instantaneously fixed blade positions of the impeller and diffuser. The calculation of the velocity field is continued at various blade positions, neglecting the vortexes shed from blades for the sake of simplicity at the present stage, though each blade circulation of the impeller and diffuser, $\Gamma_{i}$ and $\Gamma_{d}$, respectively, is changed, with the impeller rotating as shown in Figure 4. Here the horizontal axis $t^{*}$ of Figure 4 is denoted as the dimensionless time based on the rotating time of the impeller $2 \pi /\left(Z_{i} N\right)$, meaning that $t^{*}=0$ when the center of the peripheral outlet surface of the impeller blade is located at the same circumferential position as the leading edge of the diffuser blade, as shown in Figure 5. In velocity calculation, a shape modified by the displacement thickness of the boundary layers, obtained in vaneless diffuser calculation, was used for the impeller blade but not used for the diffuser blade. 


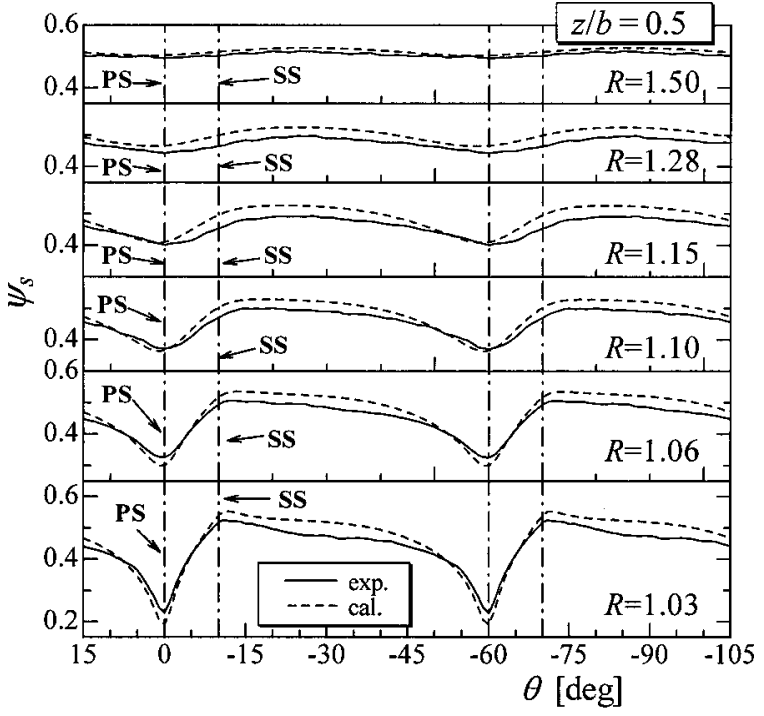

(A)

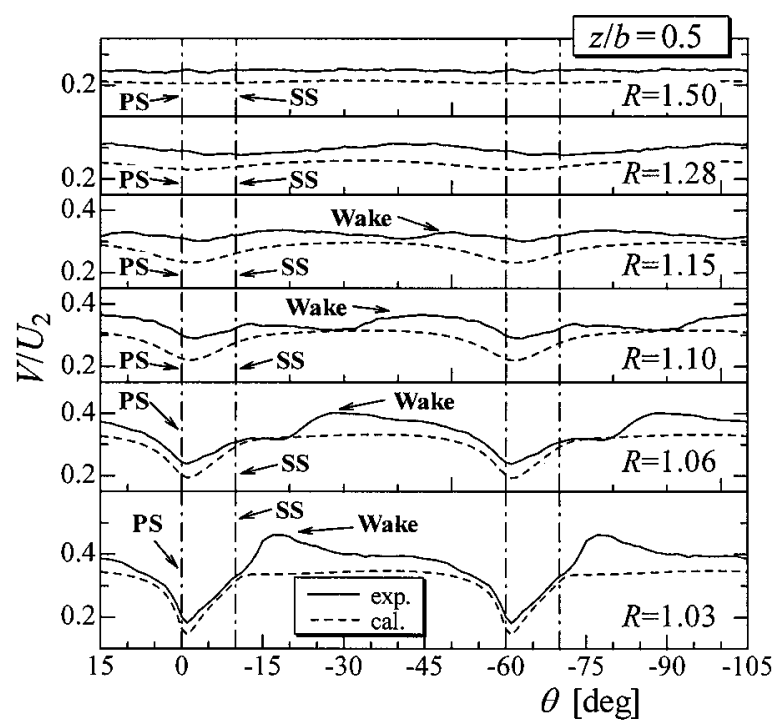

(B)

FIGURE 3

Circumferential distributions of static pressure and velocity in a vaneless diffuser. (A) Static pressure. (B) Velocity.

Static pressure can be obtained from an unsteady Bernoulli's equation for an inviscid flow analysis. The upstream condition is not prescribed for the absolute streamline through the vaned diffuser because fluid with different total pressures periodically flows out from the impeller. It is found from Figure 4 that the sum of all impeller blade circulations is almost independent of $t *$ and takes constant. This fact suggests that any streamline has the same total pressure at the infinite section of $r=\infty$ independently of $t^{*}$, as Equation (1) shows:

$$
\left.\rho V_{u} U\right|_{r=\infty}=\sum_{n=1}^{z_{i}} \Gamma_{n} N .
$$

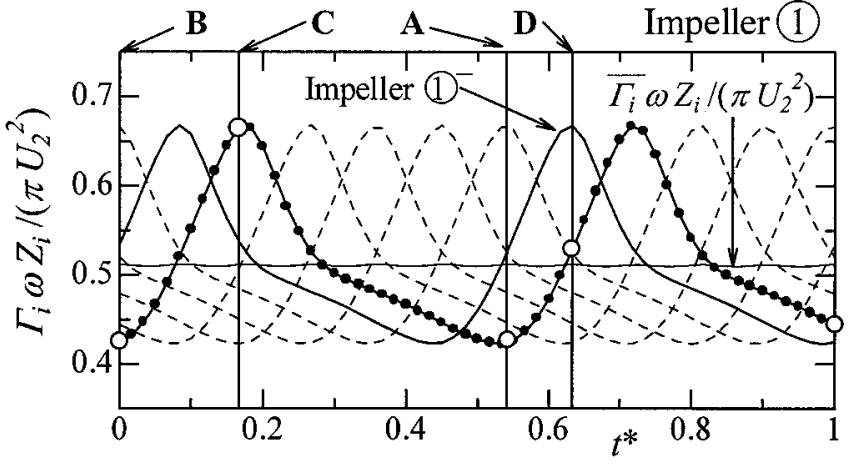

Diffuser vane (2)
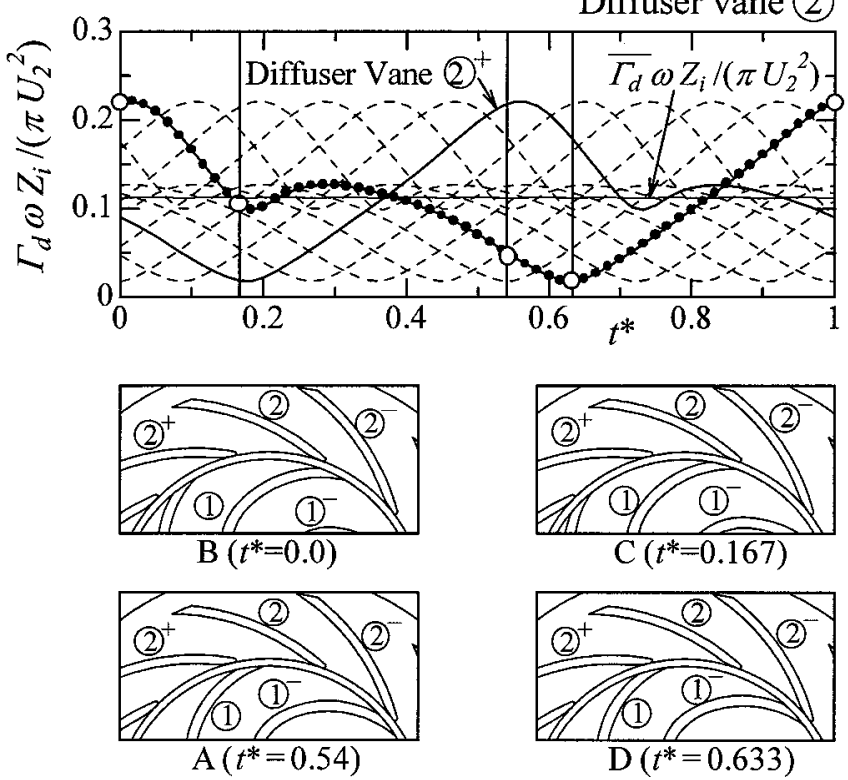

FIGURE 4

Time variation of blade circulation with impeller rotating.

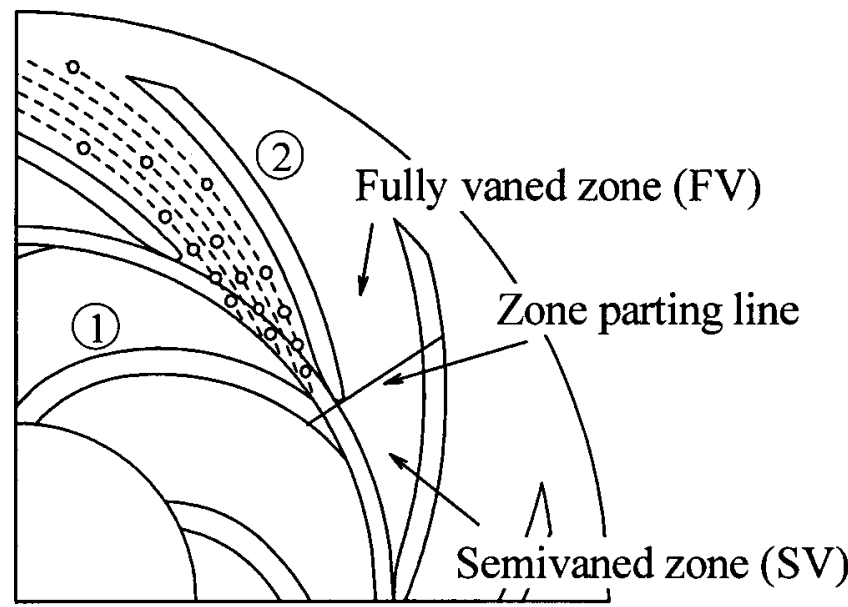

FIGURE 5

Definition of $t^{*}=0$ and fully and semivaned zones. 
Therefore, the local static pressure $p$ is related to Equation (2):

$$
p_{\infty}+\rho \frac{V_{\infty}^{2}}{2}=\left.\rho V_{u} U\right|_{r=\infty}=p+\rho \frac{V^{2}}{2}+\rho \frac{\partial \varphi}{\partial t} .
$$

Here, $\varphi(t)$ means an instantaneous velocity potential, which is obtained from the calculated discrete vortexes as follows:

$$
\begin{aligned}
\varphi(t)= & \frac{q}{2 \pi} \log r+\sum_{n=1}^{Z_{i}} \sum_{k i=1}^{K_{i}} \frac{\mu_{n k i}(t)}{2 \pi} \Delta \Theta_{n k i}(t) \Delta s_{n k i} \\
& +\sum_{m=1}^{Z_{d}} \sum_{k d=1}^{K_{d}} \frac{\mu_{n k d}(t)}{2 \pi} \Delta \Theta_{n k d}(t) \Delta s_{n k d}
\end{aligned}
$$

and

$$
\Delta \Theta_{l k^{*}}=\tan ^{-1} \frac{r \sin \theta-r_{l k^{*}} \sin \theta_{l k^{*}}}{r \cos \theta-r_{l k^{*}} \cos \theta_{l k^{*}}}
$$

in which $q$ is the specified flow rate, $\Delta s$ the length of blade surface line element, $\mu$ the vortex strength, $(r, \theta)$ and $\left(r_{l k}, \theta_{l k}\right)$ the positions of calculating and vortex points. The subscripts of $l$ in Equation (4) means $n$ or $m$ in Equation (3) and also* in Equation (4) means $i$ or $d$ in Equation (3). After calculating $\varphi(t)$ at various blade positions, the time derivative $\partial \varphi / \partial t$ is evaluated as the finite difference equation at a calculating point.

\section{RESULTS AND DISCUSSION}

Figure 6 shows the time variations of the pressure coefficient $\psi_{s}$ and the dimensionless velocity $V / U_{2}$ at measuring points at the middle height of passage $z / b=0.5$ on lines 1 (pressure side), 3 (center), and 5 (suction side) in Figure 2. Measured results are expressed as solid lines and calculated results as dotted lines in Figure 6. In comparison with the results in the vaneless diffuser in Figure 3, those in the vaned diffuser become wavier. The wake
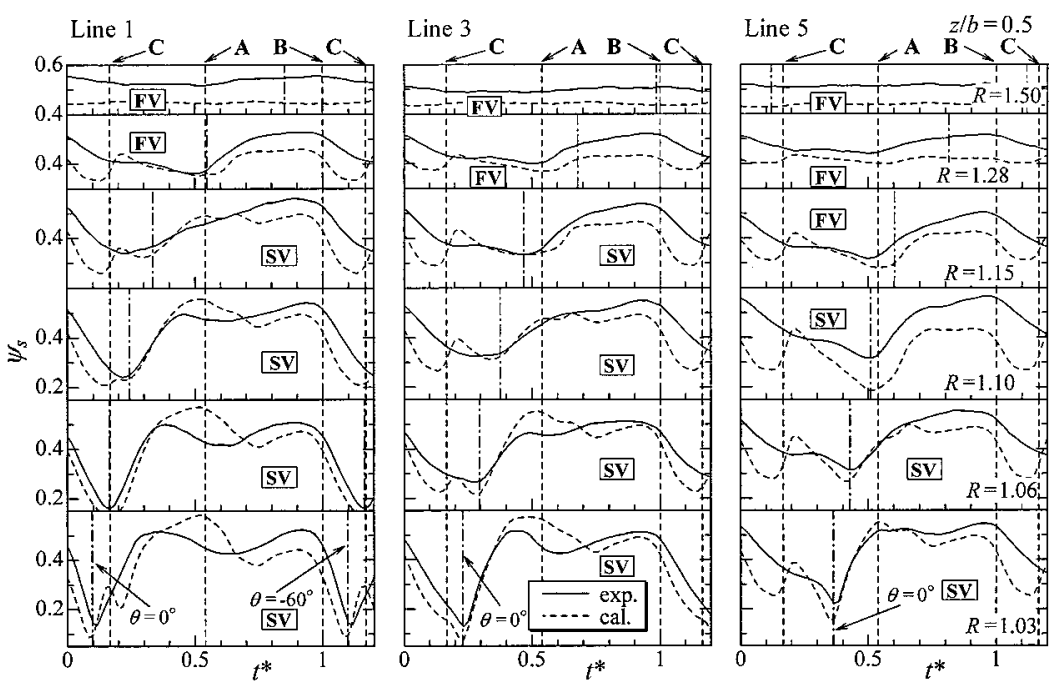

(A)
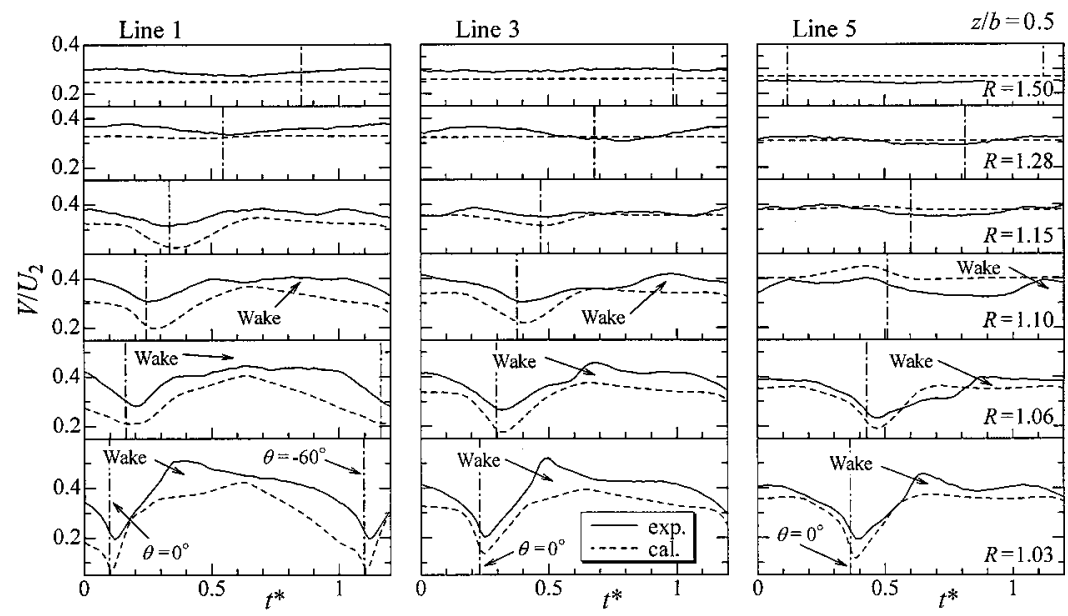

(B)

FIGURE 6

Comparison of measured and calculated results of flow fluctuations in a vaned diffuser. (A) Static pressure. (B) Velocity. 


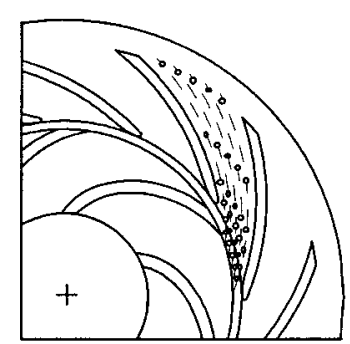

Time A

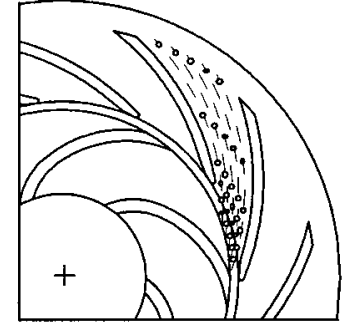

Time B

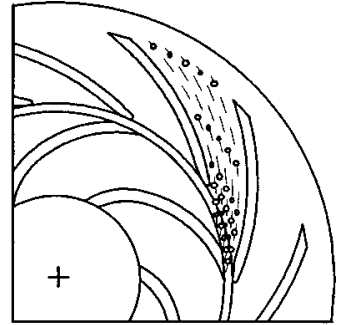

Time C

FIGURE 7

Position of impeller and diffuser blades.

region of real fluid flow, presumed on higher absolute velocity, as well as flow in the vaneless diffuser in Figure 3, is also depicted in Figure 6B.

The next three distinct points are found from Figure 6 . The passing time at the outlet edge of the pressure surface of the impeller blade through the same circumferential position $(\theta=0$ degrees and -60 degrees) is expressed as a dot-and-dash line for each measuring point in Figure 6; the passing time at the outlet edge through the zone parting line between semivaned and fully vaned zones shown in Figure 5 is also expressed as a broken line of $\mathrm{A}$ in Figure 6A. At the time line of A, the impeller and diffuser blades are located as shown in Figure 7. Then at the first point, the lowest values of pressure and velocity occur almost on dot-and-dash lines for measuring points less than $\mathrm{R}<1.15$ in the semivaned zone of SV. These variations have a phase similar to those in the vaneless diffuser in Figure 3. For measuring points in the fully vaned zone of FV, however, the lowest value of pressure appears on time line A. As the second point, pressure is rapidly decreased from time line $\mathrm{B}$ to $\mathrm{C}$ for all measuring points, while the velocity is not increased. At time B, the outlet peripheral surface of the impeller blade and the leading edge of diffuser blade are radially overlapped as shown in Figure 7. Therefore, the outlet flow from the impeller smoothly enters the diffuser passage. On the other hand, at time $\mathrm{C}$, the outlet surface of the impeller blade makes the passage inlet area narrower on the pressure side of the diffuser, and the smooth entry of the outlet flow is disturbed. At the third point, the measured pressure in the semivaned zone is slightly decreased at time $t^{*}$, which equals about 0.6 ( 0.7 for the calculated pressure) .

The time variation of the measured pressure in the vaned diffuser is more wavy than that of the velocity, as shown in Figure 6, and the variation of velocity is not so different from that in the vaneless diffuser in Figure 3B. In addition to these, the calculated results agree well with the measured results, in spite of neglecting in the calculation the vortexes shed from the impeller blade. This result implies that the potential interaction between the impeller and the diffuser blades is more dominant than the wake interaction in the case of the combination of a centrifugal impeller and a vaned diffuser. It indicates, therefore, that the present calculation is usable to discuss the effects of relative positions and shapes of the impeller and diffuser blades on pressure fluctuations in a vaned diffuser.
In the calculation, the wavy pressure fluctuation in the vaned diffuser is caused by the unsteady term of $\partial \varphi / \partial t$ in Equation (2). As the velocity potential $\varphi(t)$ is evaluated from Equation (3), the magnitude of $\partial \varphi / \partial t$ depends on the variation in the vortex
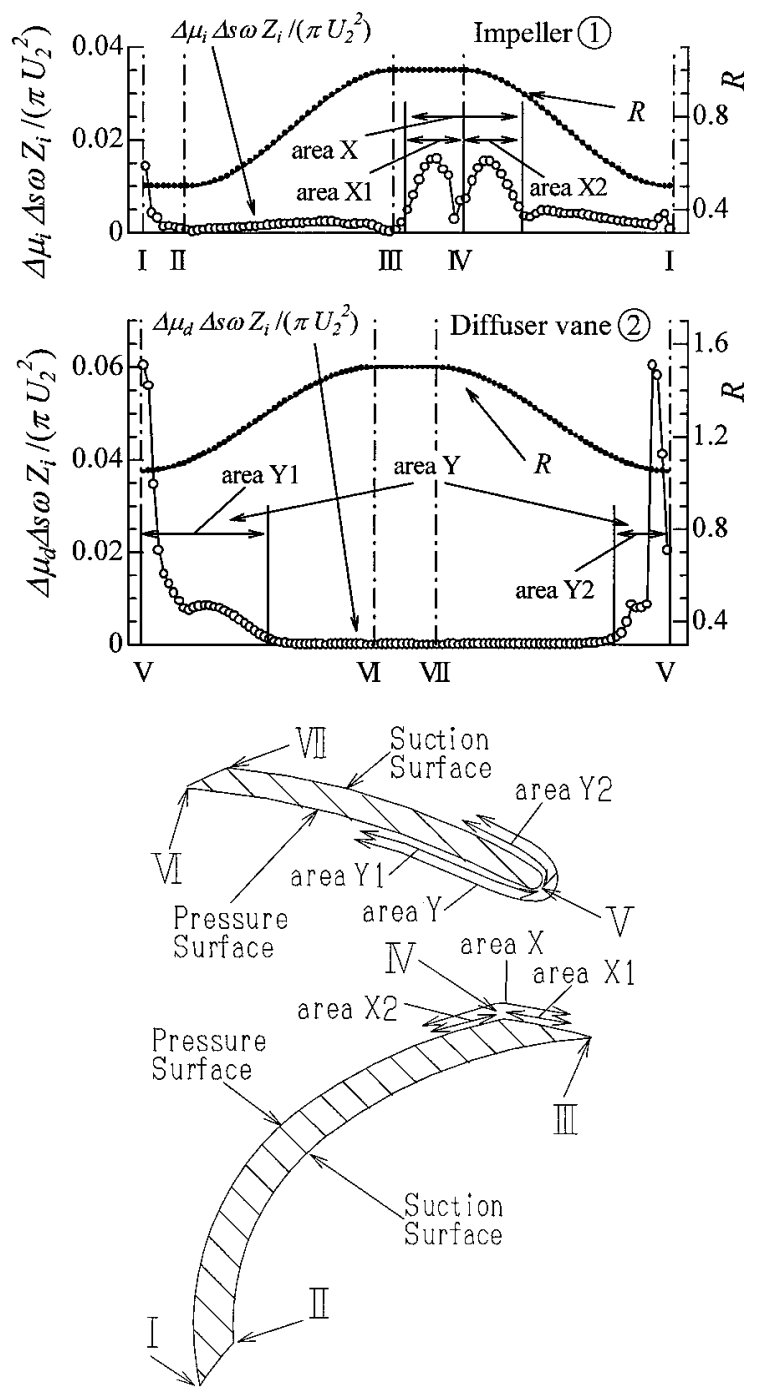

FIGURE 8

Vortex strength fluctuation due to the interaction of impeller and diffuser blades. 

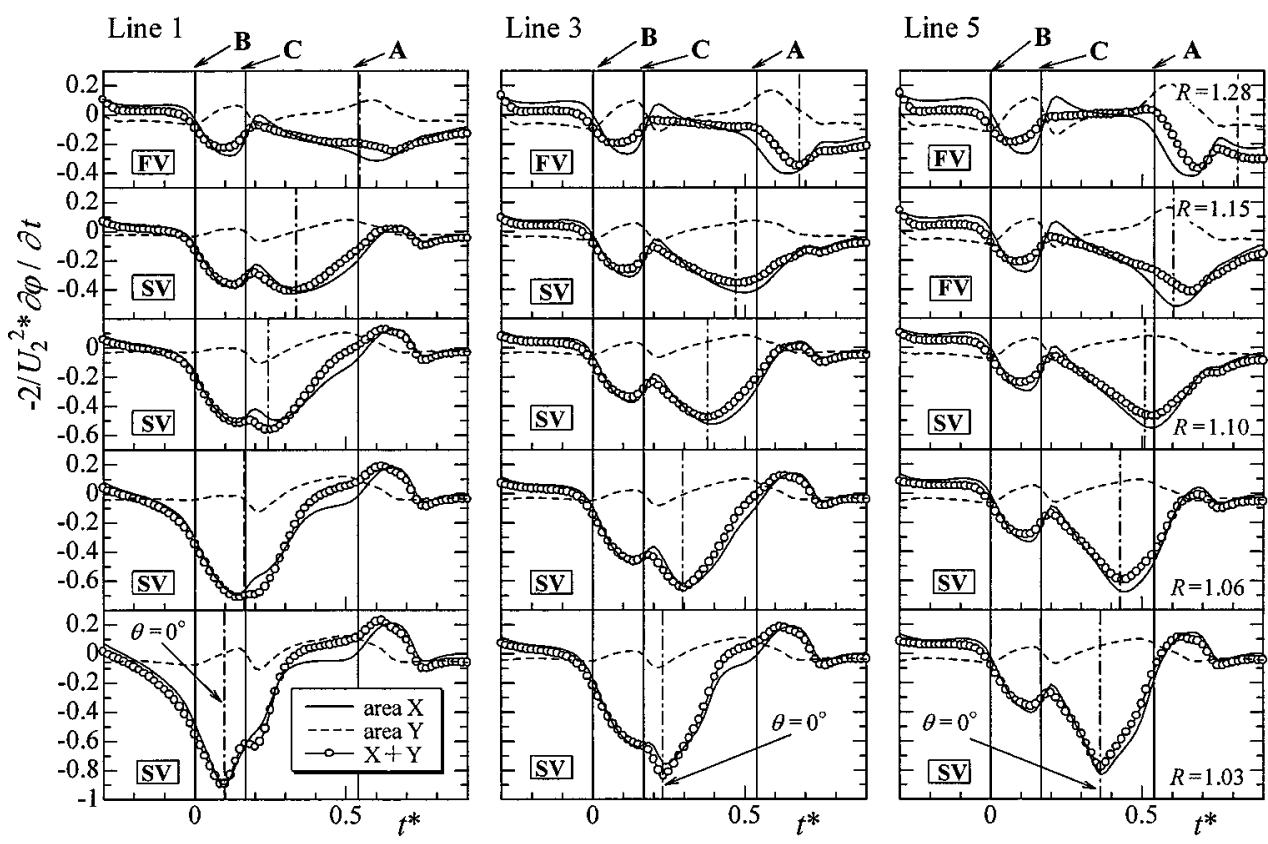

FIGURE 9

Pressure fluctuations due to the change of vortex strengths in areas of $\mathrm{X}$ and $\mathrm{Y}$ on the blades.

strength distributed on the impeller and diffuser blade surfaces. Figure 8 shows the amplitude of the vortex strength's fluctuation $\Delta \mu$ on the blade surfaces, in which positions of I to VII on the horizontal axis on the left of the figure are representative of the positions on the blade surfaces in the figure on the right. It is found from Figure 8 that the large amplitude of $\Delta \mu$ appears in the area of X near the outlet edge of the impeller-blade pressure surface and in the area of $Y$ near the leading edge of the diffuser surface. Thus, by using only vortexes in the areas of $\mathrm{X}$ of a impeller blade, of $\mathrm{Y} 1$ on the pressure surface of a diffuser blade, and of $\mathrm{Y} 2$ on the suction surface of the adjacent diffuser blade facing a passage, the time variation of $\partial \varphi / \partial t$ was evaluated at
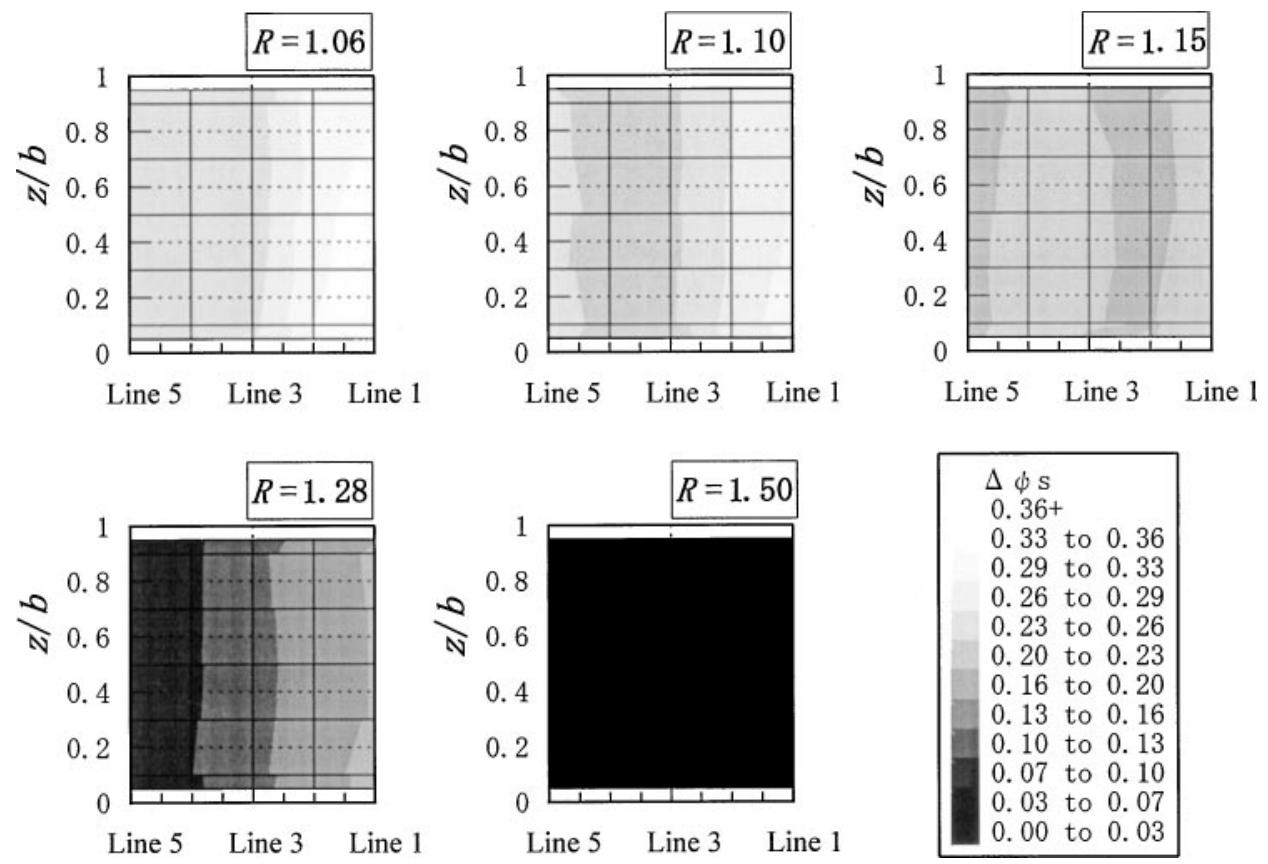

FIGURE 10

Contours of measured static pressure fluctuations in blade-to-blade passages in a vaned diffuser. 
the measuring points. Figure 9 shows the calculated results. It is found from the solid line in Figure 9 that the pressure fluctuation is almost attributable to the vortex strength fluctuation in area $\mathrm{X}$ of the impeller blade. It is mentioned on the three distinct points demonstrated in Figure 6A as follows. The appearance of the minimum pressure in the fully vaned zone cannot be reproduced on time line A in Figure 9 because of taking account of the vortexes only in the areas of $\mathrm{X}$ and $\mathrm{Y}$ in this evaluation. It is recognized, however, that the abrupt decrease in pressure from time line $\mathrm{B}$ to $\mathrm{C}$ and the slight decrease in pressure in the semivaned zone at time $t^{*}$ is about 0.7 and can be found in Figure 9. Therefore, it is known from this result that the severe pressure fluctuation in the vaned diffuser is caused by the outlet edge of the pressure surface of an impeller blade with a thick peripheral surface.

Flow measurement was performed at seven positions on the diffuser height on lines 1 through line 5 in five radial sections. After calculating the peak-to-peak difference of pressure fluctuation $\Delta \psi_{s}=\psi_{s \text { max. }}-\psi_{s \text { min. }}$, the contour map $\Delta \psi_{s}$ is obtained as shown in Figure 10. It is found that the behavior of pressure fluctuation is almost two-dimensional independent of diffuser height direction. Figure 11 illustrates the blade-to-blade distributions of measured $\Delta \psi_{s}$ in the middle-height of the diffuser, in comparison with the calculated distributions from the inviscid flow analysis. The distribution of calculated $\Delta \psi_{s}$ gives a tendency similar to that of the measured tendency. Figure 12 shows the contour of predicted $\Delta \psi_{s}$ in the diffuser passage. It is found

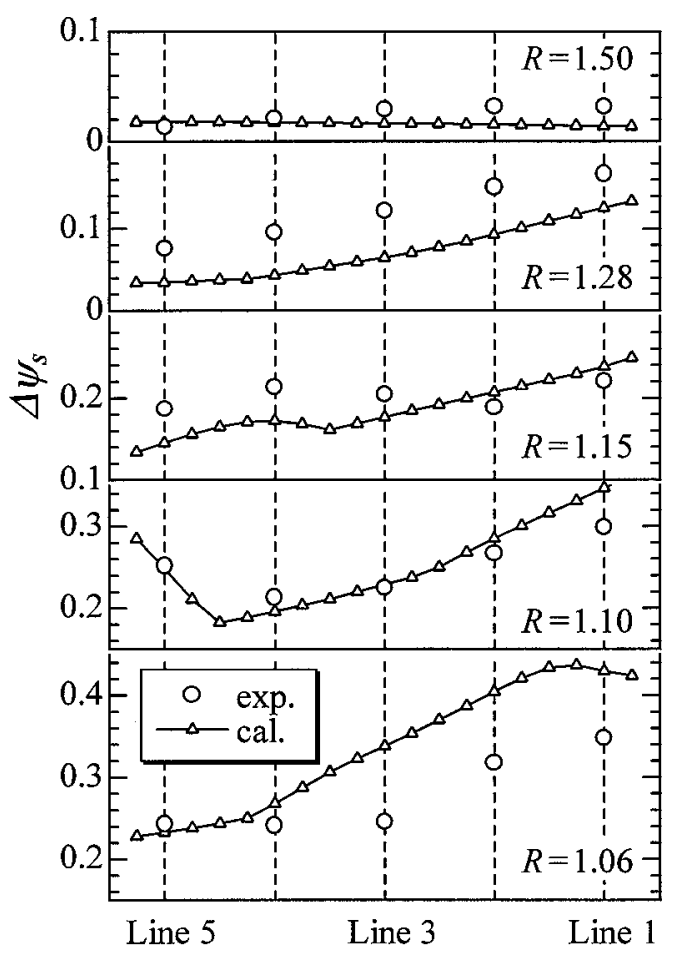

FIGURE 11

Comparison between the measured and calculated results of static pressure fluctuations.

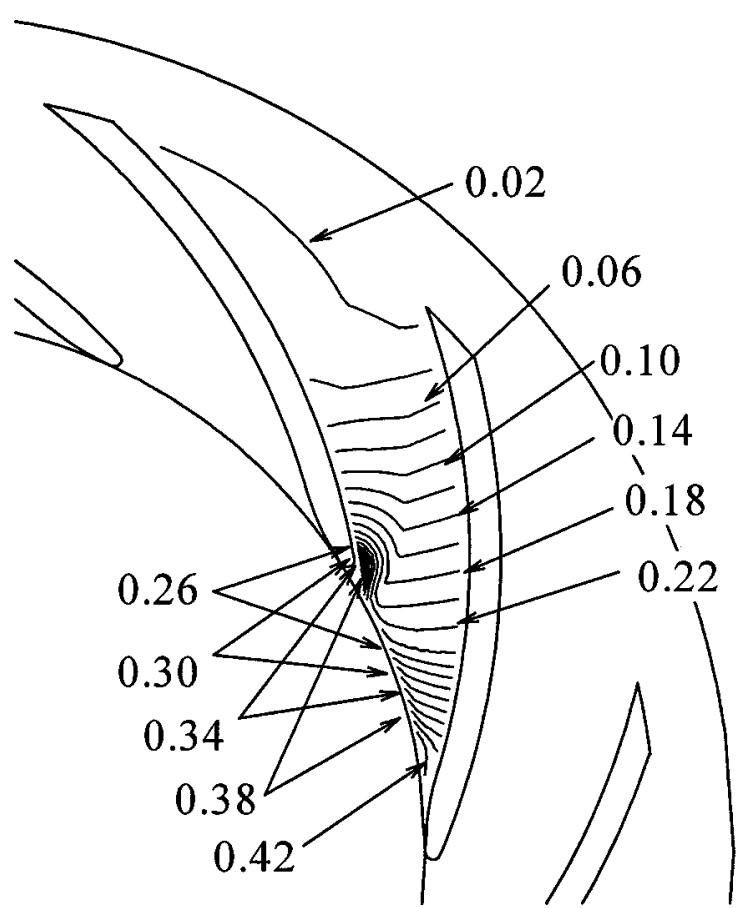

FIGURE 12

Contours of the calculated static pressure fluctuation in a vaned diffuser.

from these figures that the region of the large pressure fluctuation appears in the pressure and suction sides just downstream from the leading edge, and that pressure in the pressure side fluctuates in a relatively large amplitude. The pressure fluctuation, however, becomes weakened when it with approaches the outlet section of the diffuser.

\section{CONCLUSIONS}

The downstream flow of a centrifugal impeller in a vaned diffuser with parallel walls was measured and compared with the results calculated by an inviscid flow analysis using the bladesurface singularity method. The interaction between the impeller and the diffuser blades is discussed in this article. The results are summarized as follows.

1. The potential interaction, causing pressure fluctuation, appears to dominate in comparison with the wake interaction.

2. The flow analysis using the blade-surface singularity method, neglecting shed vortexes from the impeller blades for simplicity, enables the reproduction of measured pressure fluctuations due to impeller and diffuser blade interaction satisfactorily and is usable to discuss the effects of the blades shapes of the impeller and diffuser on the pressure fluctuation.

It should be mentioned here that the calculated results would give greater quantitative agreement with the measured ones if the effects of shed vortexes are taken into account.

3. The existence of the outlet edge of the pressure surface and the thick peripheral outlet surface of an impeller blade cause 
quite a large fluctuation of pressure during the passage of the vaned diffuser. Therefore, the outlet shape of the impeller blade should be considered in studying the problem of the interaction between the impeller and diffuser blades.

\section{REFERENCES}

Arndt, N., Acosta, A. J., Brennen, C. E., and Caughey, T. K. 1990. Experimental investigation of rotor/stator interaction in a centrifugal pump with several vaned diffusers. ASME Journal of Turbomachinery 111:213-221.

Furukawa, A., Cheng, C., and Takamatsu, Y. 1990. Studies on estimating the performances of impellers with cut-down of the blade edge of the centrifugal pumps by the surface singularity method, JSME International Journal II 33-3:525-530.

Furukawa, A., Cheng, C., Sekiya, T., and Takamatsu, Y., 1987. Flow analysis in two-dimensional impeller of centrifugal pump by surface singularity method combined with a flow-model of threedimensional boundary layer. Proceedings of the 2nd China-Japan Joint Conference on Fluid Machinery, Xi' an, 1-8.

Furukawa, A., Nakagawa, T., and Takahara, H. 2000. Downstream flow of centrifugal pump impeller in vaneless diffuser. Mem. Fac. Eng., Kyushu University 60-2:21-33.
Nakagawa, T., Furukawa, A., and Takahara, H. 2001. Flow behavior downstream of diffuser pump impeller. Turbomachinery 29-2:110118. [In Japanese.]

Qin, W., and Tsukamoto, H. 1997. Theoretical study of pressure fluctuations downstream of a diffuser pump impeller. 2: Effects of volute, flow rate and radial Gap. ASME Journal of Fluid Engineering 119:653-658.

Shi, F., and Tsukamoto, H. 1999. Numerical studies of effects of flow rate and radial gap on pressure fluctuations downstream of a diffuser pump impeller. Paper FEDSM99-7314, The 3rd ASME/JSME Joint Fluid Engineering Conference, 1-7.

Sinha, M., and Katz, J. 1999. The onset and development of rotating stall within a centrifugal pump with a vaned diffuser, Paper FEDSM997198, The 3rd ASME/JSME Joint Fluid Engineering Conference, $1-7$.

Takahara, H., Takamatsu, Y., Kouno, I., and Kurahara, T. 1989. A study on flow measurement scheme by stepwise rotation of total-pressure tube in flow with steep velocity and pressure gradients. Transactions of the JSME 55-510B:413-418.

Zhu, B., and Kamemoto, K. 1999. Simulation of the unsteady interaction of a centrifugal impeller with its diffuser by an advanced vortex method. Paper FEDSM99-6821, The 3rd ASME/JSME Joint Fluid Engineering Conference, 1-9. 

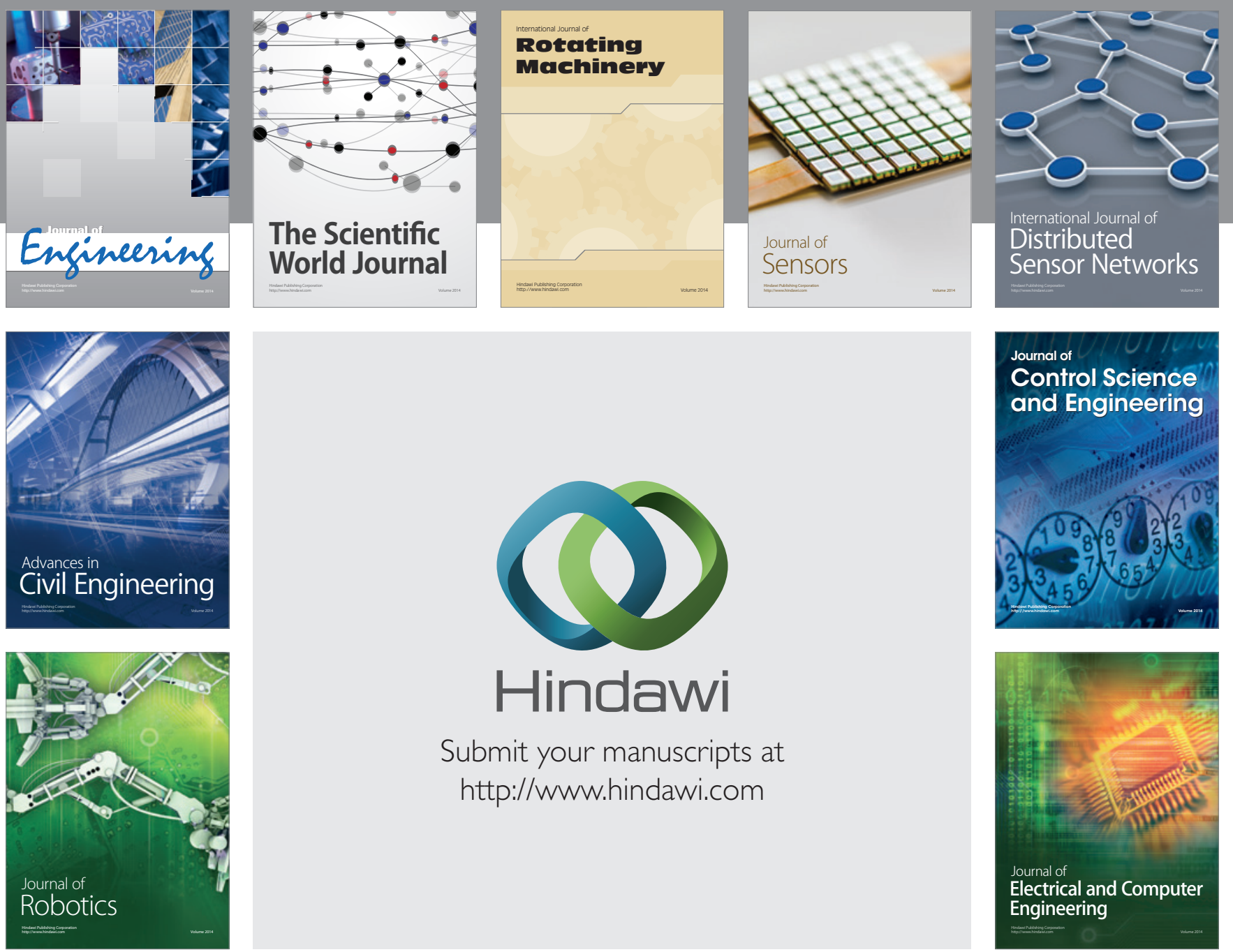

Submit your manuscripts at

http://www.hindawi.com
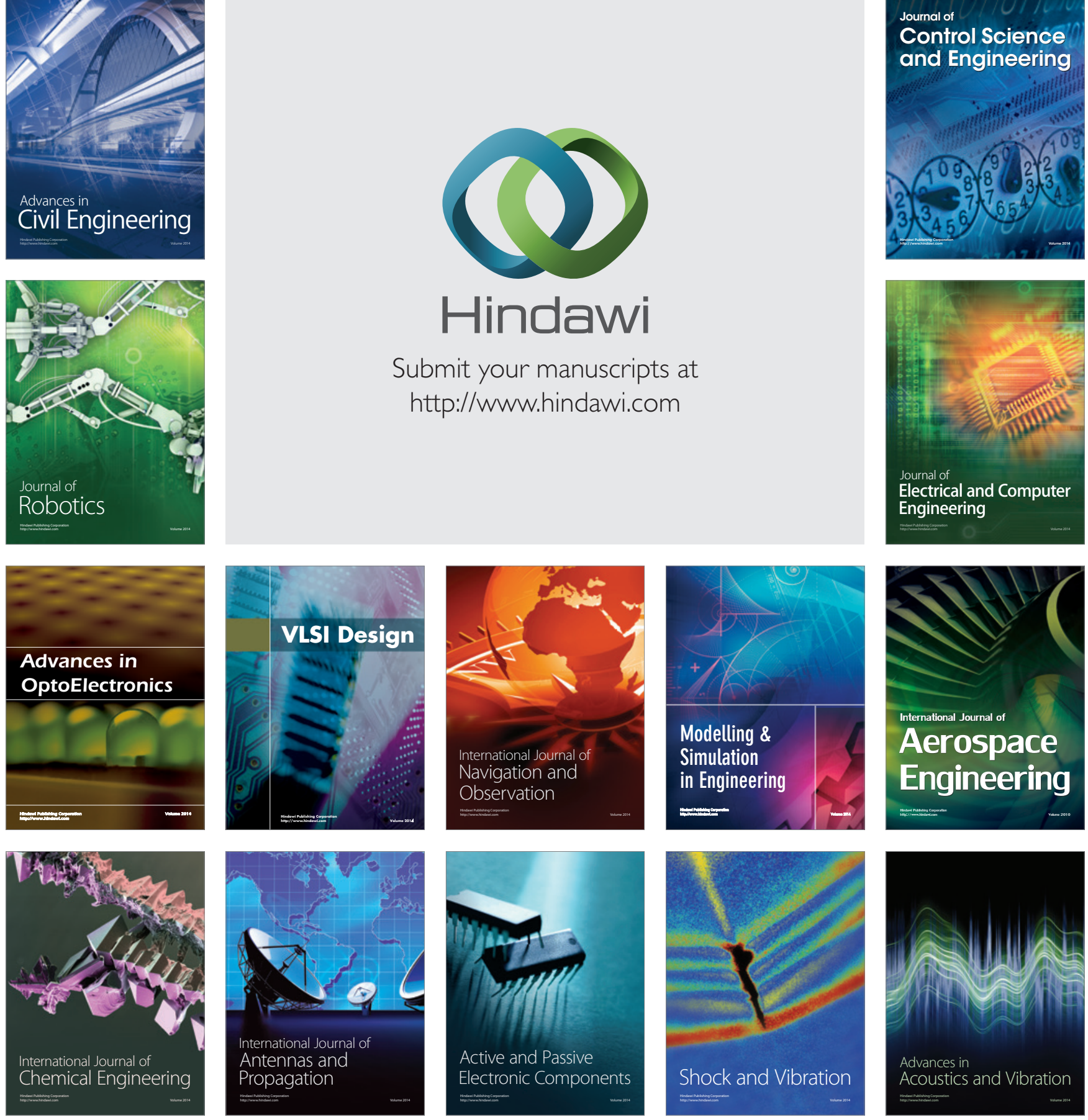